\title{
EFEITOS DO ESTRESSE HÍDRICO SOBRE O DESENVOLVIMENTO INICIAL DE CLONES DE CAFEEIRO CONILON VARIEDADE “DIAMANTE ES8112"
}

\author{
André Alves Pinheiro' \\ Wilian Rodrigues Ribeiro² \\ Daniel Ferreira Soares ${ }^{3}$ \\ Melissa Alvarenga de Oliveira ${ }^{4}$ \\ Camila Aparecida da Silva Martins ${ }^{5}$ \\ Edvaldo Fialho dos Reis ${ }^{6}$
}

Resumo: A cafeicultura apresenta grande importância para o Estado do Espírito Santo, por isso justificase estudos para compreender os efeitos do déficit hídrico sobre o cafeeiro conilon. Conduziu-se o experimento em casa de vegetação sob esquema fatorial $3 \times 2$, sendo clones de cafeeiro conilon, variedade “Diamante ES8112”, em 3 níveis e déficit hídrico em 2 níveis, num delineamento inteiramente casualizado, com 8 repetições. Os níveis de déficit hídrico foram: T0 -não sofrerá déficit hídrico e $T d$ - déficit hídrico 30 dias após plantio até as plantas atingirem $10 \%$ da transpiração relativa do tratamento T0, e após atingirem este ponto, 4 plantas por tratamento receberam irrigação diária por 30 dias a fim de analisar a recuperação posterior ao período de deficiência hídrica. Durante o período de experimento realizou-se medições do diâmetro do caule das plantas. Apesar de apresentarem comportamentos diferentes, os 3 clones utilizados no experimento sofreram influência negativa do déficit hídrico no solo.

Palavras-chave: Déficit Hídrico; Recuperação; Café; Diâmetro.

\footnotetext{
1 Graduando em Agronomia da Universidade Federal do Espirito Santo - UFES, Brasil. E-mail: aalvespinheiro7@gmail.com.

2 Graduando em Agronomia da Universidade Federal do Espirito Santo - UFES, Brasil. E-mail: wilianrodrigues@msn.com.

3 Graduando em Agronomia da Universidade Federal do Espírito Santo - UFES, Brasil. E-mail: danielufes@live.com.

4 Graduanda em Agronomia da Universidade Federal do Espírito Santo - UFES, Brasil. E-mail: melissalvarengao@gmail.com.

5 Doutora e Professora da Universidade Federal do Espirito Santo - UFES, Brasil. camila.cca@hotmail.com.

${ }^{6}$ Doutor e Professor da Universidade Federal do Espirito Santo - UFES, Brasil. E-mail: edreis@cca.ufes.br.
} 